\title{
Discussion About Teaching On Interior Space Design
}

\author{
Jiangyong Li
}

\begin{abstract}
Department of Environmental Art Design College, Hebei Institute of Fine Art, Shijiazhuang, Hebei, 050700, China
\end{abstract}

Keywords: Interior Design, Graphics Teaching System, Engineering, The liberal Arts

\begin{abstract}
Interior design is the essence of the interior space design, including physical space design and psychological space design two levels. Interior design style is an important issue for interior designers and owners. Through analysis and Research on the relationships between design and interior design style of interior space, summed up the "interior space design to create a style of interior design" and "interior design style shape the psychological space two obvious characteristics.
\end{abstract}

\section{Introduction}

Institutions of higher learning professional interior design engineering, arts, the sciences compatible. Especially its graphics teaching, engineering and arts two different directions, cultivate the students each have advantages and disadvantages. With the development of the social and economic, the demand for design professionals in the field of is diversified, therefore different levels, different types of talents will be welcomed by society. Interior design teaching should be established according to the environmental conditions of oneself and keep its teaching features, to design the teaching aim of talents cultivation, the specifications, should according to the diverse needs of society, a positive and creative response. For partial and partial arts discussed different perspectives of interior design teaching, put forward with pertinence and maneuverability of liberal arts is compatible with the teaching ideas and concrete methods of teaching. Colleges and universities such as interior design professional worker, arts and the sciences compatible. Especially its graphics teaching, engineering and arts two different directions, cultivate the students each have advantages and disadvantages. For partial and partial arts discussed different perspectives of interior design teaching, put forward with pertinence and maneuverability of liberal arts is compatible with the teaching ideas and concrete methods of teaching.

Project teaching method of enlightenment in Europe early labor thought education reform period, its shape is the 18th century education majoring in education and in the 19th century in the United States and co-operation in Europe, after a long development course, it was not until the 20th century later period tends to WanShanHua slowly, become a kind of important theory and transition to the new trend. Project teaching mode is based on the industrial society and information society system forms of modern education. It to mass production and social unity as the main content, to the educatees socialization, make educated to meet the requirements of modern productive forces and production relations as the main purpose, namely to cultivate practical talents for the society created a new model. In the project teaching method, learning process to become a creative social practice activities to one another, it pays attention to not only the final result, the more important is to complete the project process from the harvest. [1]Students in the process of project practice to pay attention to the knowledge and skills to understand and grasp the course requirements, realize the innovation of hardship and joy, cultivate the ability to analyze and solve problems, eventually form a complete set of analytical thinking mode.

Interior design is the labor, the arts, the sciences compatible discipline, discipline span is big, the talents training target and way are different from other disciplines. To conform to the requirements of talents training target, teaching methods to meet the needs of professional development must be 
to study teaching system.

On the system, open interior design professional vocational colleges exists partial engineering and the arts. Partial engineering professional interior design based on a general engineering colleges and universities, the increase in the curriculum "engineering drawing", "housing architecture" and "engineering mechanics" engineering course, at the same time in teaching emphasize the standardization, operability, and safety. The quadrature in the compasses in colleges and universities graduates, field practice ability. Design scheme is compared commonly specifications, usually has a strong operability. But their design works of imagination and artistic appeal. Partial arts major general because art college offers interior design. On the teaching emphasis on "sketch", "color" the fine arts curriculum, emphasis on visual effect, creativity and imagination. This kind of university graduate student active float in the sky, full of passion. Design solution generally show a strong emotion and individual character, but in the normative and scheme of the figure of a slight lack of operability. [2]Same profession has so different education effect, find out takes both advantages of a system should be set up interior design professional vocational colleges must be thought.

Interior design is a visual art design that is the core goal is graphics. Here graphics should cover engineering drawing, sketch, color, composition, etc. Interior designer by graphics to owner or the construction personnel to express their design intent. Therefore, research on teaching system should be put aside complex program later design theory and construction management, professional graphics system is emphatically discussed.

\section{The Teaching System}

The teaching of engineering graphics in descriptive geometry, the theoretical basis of the three view drawing as the main expressive means. Starting point, line and plane projection, to the study of geometry superposition, dig form and the three-dimensional cutting, plane projection reversal form complex three-dimensional space concept. Drawing standards its core purpose is to develop accurate $3 \mathrm{~d}$ space imagination and standardized view, drawing ability; Three view drawing and axonometric drawing is its core content of repeated interactions. The effect of forming in your mind quickly and standard three-dimensional imagination, and with AutoCAD drawing tool or means of computer aided accurately express the design intent; At the same time form a rigorous and normative logic thought. Engineering graphics recognition and its production of uncertainty is in the process of training must be strictly observed. The correctness of the graphics, can be used in the production of machining is the ultimate goal, under the size specification only has practical significance.

Art graphics on the basis of the sketch, color, combination of plane composition, color composition, three-dimensional construction, the theoretical basis of the dot, line, face and all sorts of color for elements, the research on the rules of the combination of graphics, change and unity as its core. Various elements is a means of emotion or intent and symbols. Designers through the basic skills of freehand drawing or plane computer-aided design software like Photoshop to express themselves on visual design change process; Exercise at the same time up to the standard of aesthetic imagination and creativity. Art graphics is outpouring of emotion, is to achieve the ultimate goal of the visual enjoyment, and size and drawing specification into bondage thinking factors here. 


\section{Teaching Means}

Engineering graphics teaching commonly used engineering teaching content. Teaching emphasis on abstract logical thinking ability and mathematical relationships. Lectures in the traditional model of teaching methods used more concentrated. Teaching practice has the uniformity, the answer is more stringent standards. The regular teaching program is: teaching, demonstration, practice and commented. This kind of teaching pattern from beginning to end all to carry out the strict logical science technology, scalability, and progressive. Students can in the system of teaching rigorous work habit and standardized graphics expression [3].

Arts graphics teaching generally follow the traditional pattern of art colleges, after the system theory is introduced based on the principle of correlation, for example, to visual image thinking to guide students thinking, give students leave a large space. If on a subject, first to formulate goals and objectives and the final form, students can according to the requirements of the teacher mentioned target to implement, and any method. Finally the teacher by focusing on commented give direction and the guidance of the principle. This model to the students of free space on the beginning ability, expression ability .

\section{The Teaching Mode}

On the teaching mode applied design talents as the goal of teaching mode, to cultivate the students' application ability is given priority to, emphasis on cultivating students' professional design ability, comprehensive design ability, innovation ability, to adapt to the social demand and the development of The Times. Interior design teaching should be to train in the design of the first line which has an independent design capability and can be engaged in the specific design and management of the design personnel as foothold, at the same time also should strengthen the noble moral character, to the human society sense of responsibility, has the innovative spirit and ability, have the consciousness and ability of lifelong learning, etc. The cultivation of the overall comprehensive quality.

Engineering graphics teaching commonly used engineering teaching content. Teaching emphasis on abstract logical thinking ability and mathematical relationships. Lectures in the traditional model of teaching methods used more concentrated. Teaching practice has the uniformity, the answer is more stringent standards. The regular teaching program is: teaching, demonstration, practice and commented. This kind of teaching pattern from beginning to end all to carry out the strict logical science technology, scalability, and progressive. Students can in the system of teaching rigorous work habit and standardized graphics expression. The teaching of engineering graphics in descriptive geometry, the theoretical basis of the three view drawing as the main expressive means. Starting point, line and plane projection, to the study of geometry superposition, dig form and the three-dimensional cutting, plane projection reversal form complex three-dimensional space concept. Drawing standards its core purpose is to develop accurate $3 \mathrm{~d}$ space imagination and standardized view, drawing ability; Three view drawing and axonometric drawing is its core content of repeated interactions. The effect of forming in your mind quickly and standard three-dimensional imagination, and with AutoCAD drawing tool or means of computer aided accurately express the design intent; At the same time form a rigorous and normative logic thought. Engineering graphics recognition and its production of uncertainty is in the process of training must be strictly observed. The correctness of the graphics, can be used in the production of machining is the ultimate goal, under the size specification only has practical significance.

Arts graphics teaching generally follow the traditional pattern of art colleges, after the system 
theory is introduced based on the principle of correlation, for example, to visual image thinking to guide students thinking, give students leave a large space. If on a subject, first to formulate goals and objectives and the final form, students can according to the requirements of the teacher mentioned target to implement, and any method. Finally the teacher by focusing on commented give direction and the guidance of the principle. Free space of this model to students and to the beginning ability, expression ability cultivation of graphic art on the basis of the sketch, color, combination of plane composition, color composition, three-dimensional construction of theoretical basis, with dot, line, face and all kinds of colour for the element, the research on the rules of the combination of graphics, change and unity as its core. Various elements is a means of emotion or intent and symbols. Designers through the basic skills of freehand drawing or plane computer-aided design software like Photoshop to express themselves on visual design change process; Exercise at the same time up to the standard of aesthetic imagination and creativity. Art graphics is outpouring of emotion, is to achieve the ultimate goal of the visual enjoyment, and size and drawing specification into bondage thinking factors here

\section{Teaching Defects}

Engineering Graphics Teaching. Teaching Content Relative to the Actual Demand too Much. Although most colleges and universities have to abridge of existing engineering drawing teaching materials, but due to the current teaching material from the machinery or building more professional, relative to interior design professional or too complicated. Especially in the teaching practice, the pertinence is not strong.

The Teaching Method is too Rigid. In graphics teaching in colleges and universities have used the multimedia teaching means, but due to the constraints of teaching contents and requirements, engineering model of duck is still too inflexible teaching relatively professional interior design.

The Teaching Effect have a Negative Impact. Engineering graphics teaching although exercise the student's rigorous and standard, but the teaching process is given priority to with students read and copy the diagram, rarely involves the design thinking and ideas, so most students understand only after learning the imitation, and the lack of creation. Finally on the artistic quality of interior design is slightly too inflexible.

Relative Art Students, the Teaching Requirement is too High. Interior design student was dominated by the arts enrollment admission, both in mathematics and logic thinking is relatively weak, brings to the teaching of many difficulties and contradictions, such as the student's ability to accept knowledge, logical thinking ability, and in such aspects as teaching contents, teaching process are not serious problems.

The Arts Graphics Teaching. The Teaching Target is not Easy to Control. Because the art mode of teaching emphasis on the result of personality and not standardized, make them unable to have unified evaluating standard. Problems mainly reflected on the progress and effect of control and evaluation.

Teaching Content is not Complete. Emphasize visual effects at the same time, tend to ignore the actual construction of maneuverability; Though there is a base of the three-dimensional construction at the same time, there are still many problems existing in students' imagination in space; The final construction drawings not standard or not. The most remarkable this part in the construction details.

The Negative Impact of Teaching Means. Art mode teaching method can bring huge free space, the beginning ability and expression ability. Because of the teaching target is not easy to control, however, is to put forward the high sense of responsibility to both sides of the teaching requirements. Teachers and students must have good quality and behavior of self-control. Teachers 
in particular, if there is no high sense of responsibility and certain professional attainments, is entirely possible "perfunctory, students do nothing." The situation [4].

\section{The Reform of the Teaching Method and Teaching Content}

For teachers and schools, interior design teaching and practice should be adapted to today's design market changes, we need to constantly thinking and study design teaching reform, build a set of take the market as the backing, take the student as the main body, establishing scientific personnel training mode and curriculum system, to adapt to the demand of the society.

Strengthen the training of the basic knowledge, grasps the reasonable knowledge structure Develop the students' ability of design need solid basic skills. Basic knowledge should be combined with professional knowledge, training students to the object of observation ability, expression ability, memory ability, aesthetic ability, develop their spirituality, cultivate their divergent thinking mode, reasonable knowledge structure is very important for a designer, because basic knowledge is an integral part of the overall knowledge structure. Design create presentation skills including a variety of ingredients, its knowledge structure includes not only the necessary professional knowledge, but also including philosophy, sociology, ethics, psychology, aesthetics and information science knowledge.

According to the above requirements, the interior design course on the content setting by profession needs to be adjusted, in addition to the traditional rendering techniques training, also add on3dmax, AutoCAD and other professional software, such as teaching content, some of the course content need to adapt to the current trend, such as residential space design Shiyingfang real estate development and the change of the people to live idea, combined with today's interior design decoration and assembly features, increase the students' appreciation of furniture, furnishings and environmental greening the aspects of curriculum content. Considering the need of the development of computer technology and professional learning, to open the AutoCAD, curriculum content and so on 3dmax, focusing on the training of the professional drawing software. According to unit of choose and employ persons, the many graduates are lack of the understanding of materials and their structure, lead to deviation between design and actual construction, therefore, the material and construction as an important design skills class content included in the teaching, strengthen students' ability of cognition and application of materials.

\section{The Solution}

After appropriate abridged and modify the content of the engineering into the curriculum, the teaching content of engineering drawing is necessary. It can develop accurate three-dimensional space imagination ability, understand the need of national standard drawing specification. After make art students to complete the perceptual creation in rational way to express design intent. But the teaching material content relative to the interior design for engineering professional too cumbersome, so that the students can't master the real need to master the content of the produce of the technical content of boring. In fact as long as a professional interior design students learn the basic knowledge of the "projection", "projection" point, line and plane, the form of expression method ", "axonometric projection" and directly associated with interior design basic knowledge "engineering drawing" the five part is the basic requirements. For "projection transformation", "curve and curved surface", "perspective projection", "projection" shadow "perspective transformation" and so on the content, even should belong to the students who are interested in autonomous learning, the content of the class discussion [5]. 
Make full use of multimedia technology in teaching method can make the teaching of engineering drawing is more easy to accept and master students, visual images and visual expression of image, can vividly describe the concept of both abstract and tasteless, stimulate students' interest in learning, to students as the center and guide students to think and analyze problems.

Improve the Art of Targeted whether Engineering Part of the Course or Part of the Teaching Content must be Closely around to Interior Design. Part of the arts should be as far as possible to the content of the interior design needs. Such as in the "sketch" and "color" base class teaching subjects should have a purpose to increase building indoor performance of practice. Can even courses in the architectural representation type of targeted. For engineering courses in interior design related practice instead of the civil and even mechanical teaching practice is the top priority.

Give full Play to the Role of the Computer Aided Design, Computer Aided Design as a Kind of Quick and Convenient Design Tool has an Alternative. It can omit of easel painting of a long and arduous training with his hands, and help users create the space effect. From graphic design draft jump to $3 \mathrm{~d}$ effect at the same time also have accurate and reproducible. For partial of liberal arts students can through it to develop three-dimensional space ability; For partial science students can make up for the inadequacy of hand-painted foundation weak, the computer became liberal arts interaction bridge.

Emphasizes the Interaction and Coherence in Writing by a Representative of the Actual Interior Design Example, Lets the Student in the "Effect of Hand-painted Design, Construction Drawing Design (art)-computer (engineering)-modified hand-painted effect (art)-computer performance-Modifying Construction Drawing (engineering)" Exercise such Repeated Cycle of Graphic Expression Ability. Achieve already can through the form of art, with the purpose of strict engineering graphics to express design intent. If you can't in a course or a curriculum design implementation, requires teachers to each other in all the subjects as a whole to cooperate. For example, a typical domestic outfit design, both as introduction to practice of the architectural representation techniques, and become a CAD operation problem sets, finally still use 3 class on3dmax performance computer courses teaching demonstration objects. In the process of circulation, both art and non-art students are able to read and family, and achieve the goal of arts and interactive.

It is worth noting that requires professional teachers have certain social practical experience and sense of responsibility. If there is a phenomenon of a set of design about a few years will not be able to achieve good teaching effect. Of course of higher vocational colleges in the teaching process should be hand-drawn and total design theory as the key. Although the computer aided design means has the advantages of easy to learn, accurate and reproducible, but hand-painted techniques to ensure that the creator is convenient and fast "brain - hand - paper" interaction. At the same time to explore the basic content of interior design is still graphics and design theory. Can leave these, although in the short term to develop a large number of graduates, and socially acceptable but they always just draftsman rather than a designer.

The early stage of the interior design should be determined by the artistic style and thinking form the beauty on the vision impact. In the later in engineering graphics for accurate analysis of the perfect to express design intent. Interior design professional graphic core target of teaching system should be: to create from the view of art and design, but use engineering design methods to express; In engineering of rigorous to illustrate the art of romance. 


\section{The Problems Existing in the Modern Interior Design Teaching.}

Interior design course teaching is different from other subjects teaching, has a strong practical and general sex. Inside the room design teaching should not only focus on the theory of knowledge teaching, to cultivate students' ability in practical design. As the body is made of developing and perfecting market economy, to with the more fierce competition, and interior design field need is comprehensive high-quality talent, should not only has the specialized theory knowledge also has hands-on design. The traditional interior design teaching model has some flaws, has not adapt with the development of The Times, gradually interior design teaching reform is of great significance. The problems existing in the modern interior design teaching mainly has the following several aspects.

Backward Teaching Mode. Interior design course teaching in colleges and universities is the most used still is cramming education, teachers as the main body, constantly to students with the knowledge behind this kind of teaching method, teaching mode and teaching efficiency is low, the old one has a certain ills. Teacher education is just simply to finish their teaching goals, while ignoring the students accept knowledge ability, teaching methods focus on the surface, only makes the students learning efficiency is not high, low interest in learning, and lack of practical ability of exercise. The traditional teaching mode, not only reduce the teaching efficiency and teaching effect, but also for the cultivation of the students' comprehensive quality and ability also has many adverse effects.

Theory with Practice, Training Target Lack of Pertinence. Counseling practice, and practice verify the theory, the disconnection between theory and practice, for interior design teaching has serious adverse effects. Interior design teaching in the teaching practice, the theories have very good guidance function. In the current efficient interior design course teaching, the teachers are mostly focus on theoretical teaching, and ignore the practice teaching, the cultivation of the students' comprehensive quality. Without auxiliary teaching the theory of practice, can appear empty and abstract the lack of appeal, do not have a guiding, causes students to learning more difficult. Lack of practice teaching, student appears to understand the theoretical knowledge of fuzzy phenomenon, causes students to lose interest in interior design, and basic quality cultivation is not a comprehensive. On the other hand, this way of teaching and depending on the interests of students, teaching is not conducive to stimulate students' interest, make students lost direction.

\section{Interior Design Teaching Reform Methods}

To Strengthen the Foundation and the Teaching of Theoretical Knowledge. In the interior design curriculum teaching, the basic knowledge teaching and theory teaching is the foundation of the whole teaching, is a key link in the teaching. When undertaking interior design teaching, pay attention to basic knowledge and theory of knowledge teaching, build the foundation of knowledge structure, lays the foundation for the interior design of the whole study. Interior design is a strong comprehensive discipline, as well as a cross subject, involves many fields, such as art, aesthetics, architecture, and materials science are linked. The edge of the interior design as a comprehensive discipline, the accumulation of basic knowledge and theory knowledge is very important. Interior design teaching, need to start from basic knowledge and theory knowledge teaching, to indicate the development direction of interior design teaching. Pay attention to basic knowledge and theory of knowledge teaching, not only in a definite degree make up for the insufficiency of the traditional teaching mode, but also for the interior design teaching reform provides a effective way. 
Improve and Expand the Administrators and Teachers' Professional Knowledge Level of Teachers is the Fundamental Education, and Teachers' Professional Quality Directly Affects the Teaching Effect. Improve the professional quality of teachers, be helpful for the completion of tasks of teaching efficiency and teaching, more can develop the students' comprehensive quality and ability, and cultivate more excellent talents. Teachers must have good professional knowledge level, knowledge should not stay in preparing a class lecture stage, also should not pay attention to basic knowledge and theory knowledge teaching, teachers should adapt to the development of The Times, constantly update their knowledge structure, to accept and absorb the advanced teaching ideas, improve the quality of teaching. Teachers to update their knowledge structure, but also to adapt to the development of The Times, the teaching idea and teaching model also must carry on the reform and innovation. In the colleges and universities teaching, to build a branch of high-quality talent team of teachers, to rise the teaching quality, better room The design course teaching. Is a straight in a constantly changing market, teachers only constantly enrich himself, update their ability to meet the needs of times development, in order to cultivate excellent talents. Improve teachers' professional knowledge level, is not only beneficial to the improvement of teaching efficiency and teaching effect, also can help students better adapt to rapidly changing market, improve the students' employment rate.

Establish Proper Talents Cultivation Target and the Main Teaching Body Interior Design Course Teaching Goal is to Train Talents with good Professional Quality, to some Extent This Highlights the Talents' Training Goal. Employment oriented to establish talents training target, helps to cultivate qualified personnel to interior design, to improve students' employment rate.

Pay Attention to the Cultivation of Students' Practical Ability. Practice ability including the ability to model making, computer aided design. American art design education on the arrangement of the course, students' practice and part accounted for more than eighty percent, visible to develop students' manipulative ability of practical value. Some developed countries in art design teaching and curriculum difference is very big, but have one thing in common, is all attach great importance to the course and practice course of technology study, emphasize the cultivation of the students practical ability.

Emphasize the Cultivation of Students Creative Thinking. The essence of art design is to create. A good design is often effective bright ideas, and good ideas are the designer of creative thinking and flash. Art and design have no standard mode, no common standard, also have no unified the answer, but to make public individual character and creativity as its characteristics. Creativity is the life of art and design. New and novelty and personalized design. Whether it is interior design, fashion design, product design, advertising design, and visual communication, etc., without exception. The never-ending pursuit of innovative creativity, a brand-new visual impact, is the basic characteristics of art and design. So the art design education emphasizes to create consciousness and the cultivation of creative thinking and training, think beyond the existing and development as a constant belief. Emphasis on into the thick of life, cultivating practical talents. Art design is a kind of art reality, compared to pure art, closer to the society, and close to people's life. Life can only into the thick of life, good at observation, to create a design conforming to the requirements of the society

Develop talents training target, teaching activities carried out on the one hand to revolve around employment as the guidance, on the other hand also should pay attention to build a sound teaching system establishing and perfecting the system of course teaching, based on project integration of teaching practice, knowledge and theoretical knowledge to improve students' ability to master in jobs. College teachers in the interior design teaching, pay attention to guide students to set up the 
correct outlook on life and values, cultivate students for jobs love emotion, improving students' comprehensive quality and ability.

\section{Conclusion}

Due to the closer to the actual course content more concise, method of teaching students more easy to accept; Practice project combined with the multimedia teaching, and the case analysis, targeted follow the market development, cooperate with landscape practice, improved the students' learning enthusiasm, also added a employment channels. Of course, these measures still need to improve, the exploration of teaching reform will continue. In order to improve the quality of education, interior design must be under the guidance of spirit of innovation, change of teaching, all-round, multi-angle exploration, from the requirement of social development for talent quality interior design, to establish perfect interior design teaching system. With the development of the era and the continuous improvement of the market economy system and the more intense market competition, only good people can place in the fierce market competition. In the interior design teaching, to reform the teaching methods, improve the level of teachers' professional knowledge, establish proper talents training target and curriculum system, at the same time in the make up the shortages of the traditional teaching way, the way of teaching reform and innovation, improve teaching efficiency and teaching effect to cultivate the comprehensive high-quality talents, so as to adapt to the fast development of the market. In the interior design teaching, to reform the teaching methods, improve the level of teachers' professional knowledge, establish proper talents training target and curriculum system, at the same time in the make up the shortages of the traditional teaching way, the way of teaching reform and innovation, improve teaching efficiency and teaching effect to cultivate the comprehensive high-quality talents, so as to adapt to the fast development of the market.

Pay attention to teaching mode of exploration and innovation, foster strengths and circumvent weaknesses, create characteristic, pay attention to the interior design teaching method improvement, constantly improve the quality of teaching, make interior design teaching adapted to the development of The Times.

\section{References}

[1] Zhang Licui. Research on the teaching reform of interior design in Higher Vocational colleges. Curriculum education research. 2012 (2): 1-3

[2] Zhang Jing. On the reform of teaching mode of interior art design in Higher Vocational colleges. Journal of science and Technology 2010 (10)

[3] Zhang Qi-man, Pan Wuhua. Interior design data set 2 [M]. Beijing: China Building Industry Press. 1999

[4] Hong Yi-Min. Reform the teaching method [J] training innovative talents. Beijing: Chinese Journal of Women's College. 2008 (4)

[5] Pan Wu-hua. Indoor display art design. Beijing, China Building Industry Press, 1999 